\author{
Dan M. Duse*, Carmen S. Duse*
}

\title{
CREATIVITY AND INNOVATION IN ENGINEERING EDUCATION
}

\section{INTRODUCTION}

Engineering creativity is vital in the innovation process. The decisive role in deveoping the creativity of engineers is determined by the universitary education. As to this we can affirm that the engineering education has an essenntial role in promoting our world's equilibrium, equity and sustainability, world that is in continous change. Today, the three chalanges imply the education and specialization of engineers in order to achieve products and services out of regenerable reources. In a technological interdependent world, we can say that a better education for engineering students is the main goal of research for the engineering education.

What makes the young student creative? And what is the reason why some persons are more creative than others? Often we consider that certain persons theos who have rare, unusual abilities.

The theorie of creativity render evident that craetive persons are those who take good decisions [1]: ...to buy ideas cheap and afterwards to sell them expensive. This theory an investment in creativity has been stated in 1995, by Sternberg and Lubart [2], and their observations underline the novelty and value of their creative ideas. A retrospective glimpse on creative ideas outlines their initial rejecting characteristic made individual but also collective, either on literary, art or scientific valuable papers.

From the innovation perspective one makes on ideas, this will convince other people regarding the authenticity and utility of the idea, on one hand, and on the other hand it is

* University Lucian Blaga, Sibiu, Romania 
trying to obtain their appreciation for his/her ideas looking for e recognition of his/her individual merits. Referring to this reason we come to the american researcher Maslow who considered the selffulfillment as the peak of human necessities. Creativity is considered to be one of the aspects of selffulfillment, as Maslow described it in 1968 . In addition to that he appreciates that the limitation of creativity on his products is a limited vision on them.

Maslow situates himself above on traditional researcher's convictions who regarded creativity exclusively as a means of obtaining something new and useful. He resembles creative humans with joyful and selfconscious children and consideres society an inhibition factor that alterate someones creative personality. He states that creative people see also the abstract, the general, the systemic, synoptic and the cathegories. Creativity is expressing itself in all branches of personal and professional life by means of world perception and developing oneself. Creativity means to develop one's talents, to lean how to use one's aptitudes. Creativity can be taught/learned and the creative trainingcan be done $b$ means of stud disci[lines [3].

We descover easily creativity with small children and more difficult with mature people; grown-ups, likewise, have the creativit potential altered by society which encourages and promotes the intelectual conformity. Creativit is eail accepted as being a decision, an attitude towards life, like ability. The American researchers Sternberg and Lupart have pointed out in their succesive papers $[2,4]$ that we can act on three types of abilities in order to develope creativity; these are synthetic abilities, generating new and interesting ideas:

- Analitical abilities, of critical thinking. People use this abilit for descovering their ideas implications.

- Practical abilities by means of which the theoretical idea is transposed into a practical one, abstract ideas transposed into practical accomplishments. Sternberg's investitional theory draws us the attention on an aspect alread known, ideas as good as the can be are not selling tehmselves, the person that creates them has to use his/her practical abilities in order to convince others to effectively achieve them.

It is them who evidentiated the connections between the three abilities. In observing the need for equilibrium, people that have only synthetic creativity produce novatory ideas but are not abe to revaluate them.

Those with analitical abilities can evaluate critically other's ideas ut can not easily generate creative ideas. Tle persons having practical abilities are excelent in revaluate them, can sell almost everything but produce few creative ideas.

Our preocupation in encouraging and developing creativity during the process of engineering education means actually to decover and promote the balance between 
synthetic, analitic and practical thinking. A creative attitude is at lat as important as the creative thinking aptitudes [5]. During the engineering education period one can obtain the encouragement of creativity by means of educational strategies and policies promoted by the teachers to students and faculty administrations. For the moment, the remaining question without any answer is wether teachers/professors can help students to be creative. In order to answer to this question there has benn developed a case study in two European universities, the AGH University of Science and Technology from Krakow and the University „Lucian Blaga” from Sibiu (LBUS). Students of master engineering programs and of the doctoral school of engineering for natural gas (AGH UST), as well as students from industrial engineering (LBUS) have participated. The study centers upon the analyses and the creativity test's result interpretation and of its eight dimensions. The descovery of existing binds between engineers' creativity and the job's specific competences. At the end of the research reccomandations concerning the way in which competences concerning creativity and innovation were made.

\section{CREATIVITY AND INNOVATION}

Innovation is frequently appreciated and measured by creativity. Innovation is a permanent and very important objective of organizations in their way to competence. Today, innovation has become the motor of business development [6] having favorable consequences on economy: social prosperity by means of individual and collective benefits. It is obvious that in order to become innovative and creative one has to develop aptitudes and competences. Beginning with '90, and afterwards with completions with "lifelong learning strategies" in the years 2000, culminating in 2009 with the decision "Creativity and Innovation European Year", [12] the E.U. has defined the set of eight essential competences.

The connected aptitudes to creativity are important for engineers as to allow the permanent adaptation to the changes and challenges. The meaning that universities and the whole educational system have to get is that they must combine the developing of speciality knowledge and aptitudes with the orientation capacity towards creativity (curiosity, intuition, side and critical thinking, imagination, etc). Universities have a social responsibility in preparing specialists for facing all the challenges of knowledge society. Moreover, they have to promote and motivate the appearance of new ideas and critical thought [7], to develop the capacity of team work, to provide conditions to become adapted to unusual situations, to favor the development of particular abilities and competences in accordance with personal aptitudes of each one, to promote the interest in professional practice and to favor the increase of the proper rhythm of the student. 
If the American researcher Sternberg has defined a creativity theory by means of decision and investment [1] the subsequent researches have underlined the possibility of developing "creative skills" by means of reporting on certain myths [8]:

1) The smarter you are, the more creative you are.

2) The younger you are mere creative than the old.

3) Creativity is reserved for a few - the flamboyant risk takers.

4) Creativity is a solitary act.

5) You can't manage creativity.

Antariksa proposes different tools by means of which myths can be transcended, like "the Kipling method", and "the challenge method" but also tools for creating new ideas: attribute listing", "brainstorming and visioning". In 2008 Ruger adds some other strategies for transcending myths, as: creating an environment for creativity; starting the habit of drawing; creating a personal visual library and a personal metaphor library; taking a creative and visual thinking breaks; practicing creativity; reading more fiction literature and starting a visual thinking school and in 2008, Henderson [10] defines a managerial concept as e succession of processes which can sustain the developing of "creative skills".

\section{METHOD}

In order to answer the test the main question of this paper the test of creativity was applied [13] to the two cohorts of students from the Drilling Oil and Gas Faculty (AGH) and from the Engineering Faculty (LBUS), from the master and the doctoral school programs. After the completion of the 40 items of the test each student has got the result under the form of a circular diagram (Fig. 1) which comprised the obtained general score, the specific area and the creativity dimensions specific to the engineer job. Also, explanations for understanding the eight dimensions are added.

42 students, 2nd study year, belonging to the engineering drilling and gas faculty, master programs (19\% women and $81 \%$ men) and from the doctoral school all 6 students (5 men and 1 woman) have answered by the online completion of the creativity test.

The results obtained for master programs are shown in Figure 2 and Figure 3 presents the results of the doctoral school. At the doctoral school the area of creativity specific to the engineer job has surpassed $83 \%$, as for the master programs the value obtained has surpassed it, being $40.5 \%$.

At the school of industrial engineering, master programs, belonging to ULBS, 70 students and 8 students from the doctoral school have answered by completing 
the creativity test ( 4 men and 4 women). The results obtained for the master program are shown in Figure 4 and for the doctoral school in Figure 5. The Romanian students, the master program have surpassed the specific creativity in a percentage of $52.8 \%$, and at the doctoral school in a percentage of $62.5 \%$.

\section{$\Delta$ \\ CEST MTYVITY}

\section{Your creativity score is $\mathbf{7 9 . 8 7}$}

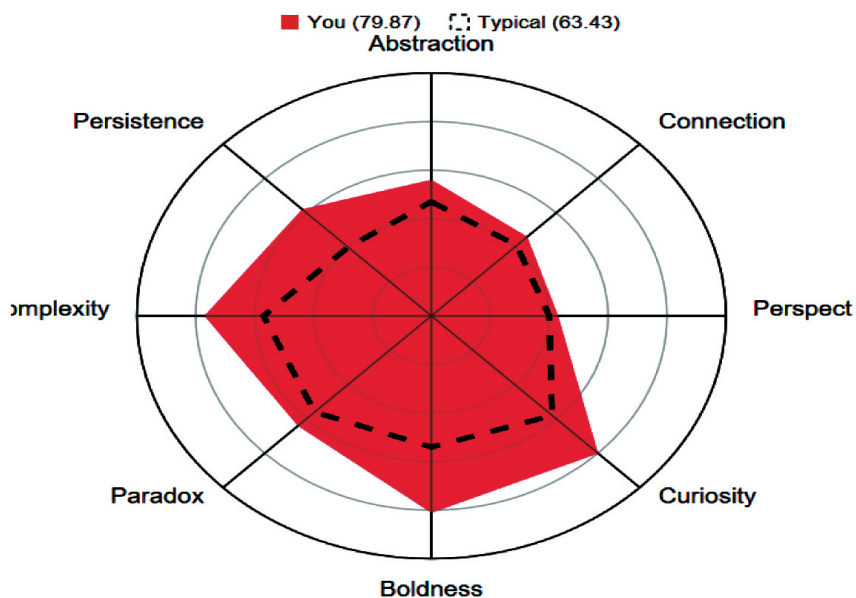

\section{How creative are you? Take the test}

Explanation of different metrics

Abstraction The ability to abstract concepts from ideas Connection The ability to make connections between things Pert dintially have an apparent connection Perspective The ability to shift ones perspective on a situationCuriosity The desire to change or improve things that everyone alse accepts as the norm

Boldness The confidence to push boundaries berond accepted conventions. Also the ability to eliminate fear of what others think of you Paradox The ability to simultaneously accept and vork with statements that are contradictory Complexity The ablitity to carry large quantities of information and be able to manipulate and manage the relationships between such information

Persistence The ability to force oneself to keep trying to derive and stronger solutions even when good ones have already

of creativity

Fig. 1. Circular diagram of creativity

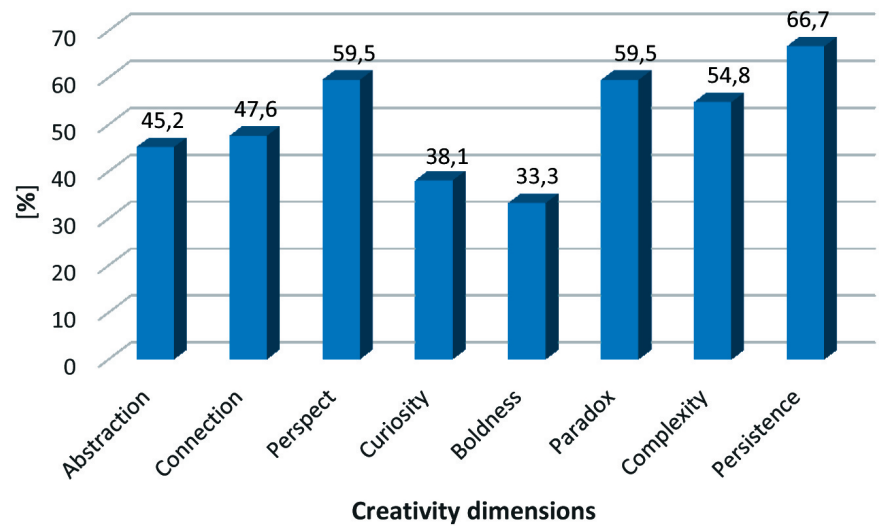

Fig. 2. The percentage of the students of a master program at AGH, with a creativity above the average of the engineering profession 


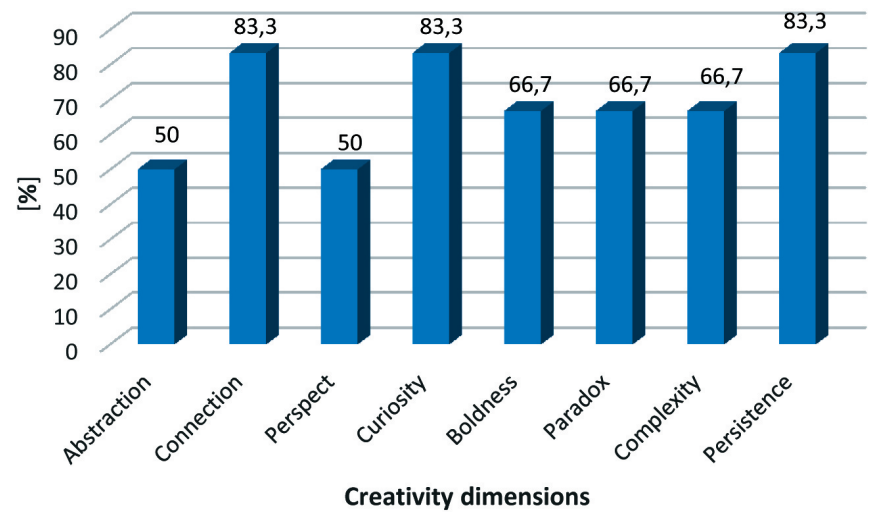

Fig. 3. The percentage of the Ph.D. students at AGH, with a creativity above the average of the engineering profession

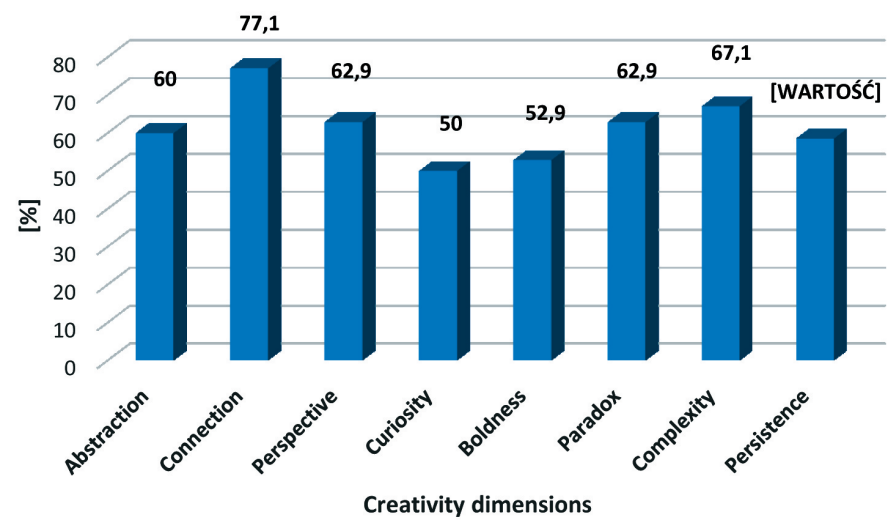

Fig. 4. The percentage of the students of a master program at LBUS, with a creativity above the average of the engineering profession

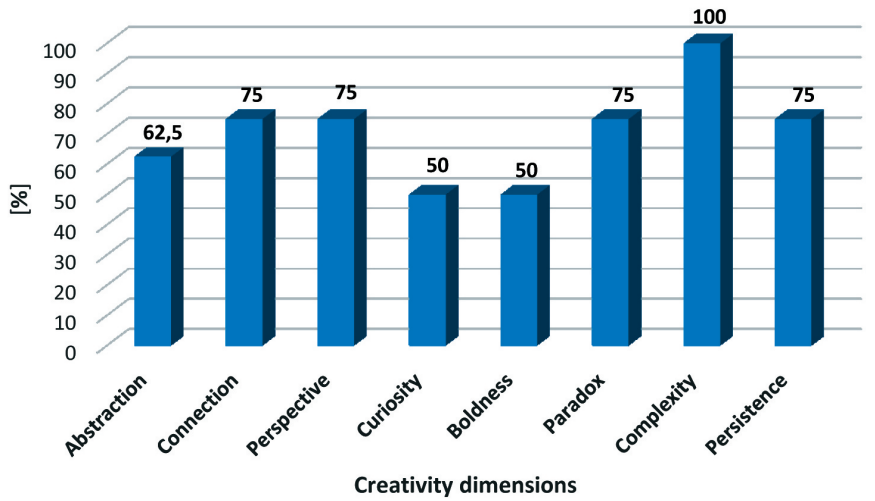

Fig. 5. The percentage of the Ph.D. students at LBUS, with a creativity above the average of the engineering profession 


\section{RESULTS}

When attentively looking at the sense of the creativity test dimensions one can observe that for the engineering job the connection, curiosity, courage, complexity and persistence dimensions have a determining role in obtaining performance while practicing the profession. The doctoral school needs specific abilities for research, during the study years as well as after that, in integrating the engineering doctors within the research-developing organizations, within universities and organizations of industrial production. Here the outstanding abilities are those of abstraction, connection, curiosity and courage, of complexity and persistency. Indifferent of appreciations on abilities prevailing in practicing the engineering profession, respectively engineering doctor, all eight dimensions are essential for the profession.

From the perspective of results obtained after testing the students we can observe a greater and very great importance of Polish master students, having great abilities on the capacity of changing the perspective of people on certain situations, but also in terms of space and time, working in paradoxical (contradictory) situations, in managing rich information, but also being insistent in order to obtain good solutions. The Polish doctorate students have outstanding results, with great and very great percentages on six out of the eight dimensions, distinguishing themselves on the capacity of making connections, on the wish to change and improve things and on the courage to push limits beyond the accepted conventions. They have obtained 50\% average percentage on abstraction and capacity of changing the perspective of people in given situations.

During the master programs, the Romanian students show good and very good results for the majority of creativity dimensions, obtaining a very great value on the capacity of making connections (71\%). The average zone is with them the wish to change and better things $(50 \%)$ and the ability to force limits, beyond the accepted conventions (52.8\%). Generally, the doctoral school has good students in all creativity dimensions and notable results are to be found with the ability of processing great quantities of information (100\%); over $75 \%$ of the students show good results in their capacity of making connections, in changing the perspective, in working with contradictory information and to force the obtaining of solutions.

The average results of $50 \%$ are present with the wish of changing and bettering things, as well as for the courage in pushing the limits beyond the accepted conventions.

Indifferent to their belonging to the master programs or doctoral school, there are dimensions which are common to the Polish and Romanian students. These are the complexity and persistence - as strong points, and curiosity, as well as courage are the common weak points (except for the Polish doctoral school). The probability of being 
a characteristic for the millenary generation is very possible, as what most students are used to do:

- Consumer orientation.

- Assumption that institutions are corrupt and untrustworthy.

- Multi-tasking:

- doing several things at once;

- learning from several different sources.

- Pragmatic approach to problem solving.

- Questioning the veracity of information.

- Entertainment orientation.

- Instant gratification.

- Short event horizon.

- Expectations of excellence.

- Awareness of personal safety.

- No civility.

\section{CONCLUSIONS AND IMPLICATIONS FOR PRACTICE}

In the UE, the master programs and the doctoral school programs belong to the three Bologna cycles of educational process. The university curricula is approved by the faculty councils, as being a fix parameter of the present research. Courses, applications and research projects are the didactic activities which are developing and courses and research projects are for the doctoral school.

(I) As a conclusion, our recommendations for developing and bettering creativity refer to teaching and interacting between teachers and students, in order to apply the twenty-four tips for creativity [1]:

The first general recommendation, indifferent of the nature and type of activities refers to the fact that the most powerful way to develop creativity in engineering education is to be a role model. At the same time make questioning a part of the daily course exchange.

The course activities are traditional, with these two universities, with the frontal teaching dominant, caused sometimes by the great number of participating students. The themes and subjects are interdisciplinary, so that teaching students to cross-fertilize draws on their skills, interests, and abilities, regardless of the subject. 
Students learn already in courses that creative people take sensible risks and produce ideas that others ultimately admire and respect as trend setting.

In their dialogue with teachers students can be wrong, professors are often unforgiving of mistakes. When the students make mistakes, ask them to analyze and discuss these mistakes.

Describe the obstacles which you, friends, and famous people have faced while trying to be creative, because the students may think that obstacles confront only them. Assuming of responsibilities concerning both success and failure.

Their interaction with the environment is appreciated as being creative. Teach students to discover and develop the ability to choose environments that stimulate their creativity. The environment for generating ideas must be relatively free of criticism.

(II) The research project activities are as favorable to developing creativity as the participant group of students is small and the projects' approach can be individual and/or of the group. The project's themes are at the disposal of the teacher who can include elements of creativity development. As a result, the following recommendations may be of great help for the teachers:

Promote creative performance by encouraging your students to define and redefine problems and projects. Encourage creative thinking by having students choose their own topics for papers or presentations.

Give time to creative thinking, most creative insights, however, do not happen in a rush. Reward creative ideas and products, reward creative efforts.

Teach students to be patient, part of being creative means being able to work on a project or task for a long time without immediate or interim rewards.

Help students to discover what attracts them, what they really love, helping students find what they really love to do is often hard and frustrating work.

The strong points of students are their richness, teach them to treasure it and take care of it, show students how to play to their strengths.

(III) The activities of type applications are fit for developing creativity in applying the recommendations made for the course as well as for the project, choosing the most suitable ones. It is important not to forget the creativity evaluation activity which can be successfully done, in this context.

At the end of this recalling on methods and means of developing creative skills, the twenty-four tips of developing creativity, developed in 2013 by Sternberg are very actual but one can add also that, the model of creativity is the best represented by imagination in teaching. 


\section{REFERENCES}

[1] Sternberg R.J., Grigorenko E. eds.: The Psychology of Abilities, Competencies, and Expertise. Cambridge University Press, Cambridge 2003. ISBN 9780521809887.

[2] Sternberg R.J., Lubart T.I.: Defying the crowd: Cultivating creativity in a culture of conformity. New York, Free Press 1995.

[3] Maslow A.H.: New Knowledge in Human Values [Ed: Abraham H. Maslow]. Harper \& Bros, NY1959, South Bend, IN:Regnery/Gateway, 1959.

[4] Sternberg R.J.: Beyond IQ: A Triarchic theory of human intelligence. Cambridge University Press, New York 1985.

[5] Schank R.C.: The Creative Attitude: Learning to Ask and Answer the Right Questions. Macmillan, New York 1988.

[6] Darso L.: Creativity and Innovation. Francesca Pagliuca interviews Lotte Darso, 2008. URL:http://uninews.unicredit.it/en/articles/page.php?id=9284.

[7] Morales G., Morales C.U.: Model for engineering education to development of competences and abilities. Proceedings of the International Conference on Engineering and Education, Coimbra, Portugal, 3-7 September 2007, URL: http:// icee2007.dei.uc.pt/proceedings/papers/74.pdf.

[8] Antariksa Y.: Creative Thinking Skills. 2008, URL: http://www.slideshare.net/ nusantara99/creative-thinking-skills?src=related_normal\&rel $=572438$.

[9] Kelsey R.: Visual and Creative Thinking - what we learned from Peter Pan and Willy Wonka. 2008, URL: http://www.scribd.com/doc/2681453/visualandcreativethinking11974292031173484.

[10] Henderson J.: Developing Students' Creative Skills for the 21st Century Success. Education Update, 60 (12), 2008, URL: http://www.ascd.org/publications/newsletters/ education_update/dec08/vol50/num12/Developing_Students'_Creative_Skills_for _21st_Century_Success.aspx.

[11] Scott C.: The Net Generation Goes to College. The Chronicle of Higher Education, http://chronicle.com, Section: Information Technology, vol. 52, Iss. 7, 2005, pp. A34.

[12] http://create2009.europa.ue.

[13] http://www.testmycreativity.com/. 